Revista Brasileira de Farmacognosia Brazilian Journal of Pharmacognosy 23(1): 138-144, Jan./Feb. 2013

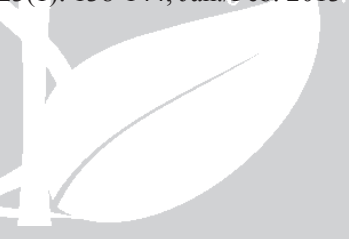

Article

Received 6 Jun 2012

Accepted 19 Nov 2012

Available online 1 Feb 2013

Keywords:

antinociception

anti-inflammation

Phyllanthus niruri

standardization

ISSN 0102-695X

DOI: $10.1590 / \mathrm{S} 0102-695 \mathrm{X} 2013005000004$

\section{Anti-inflammatory and antinociceptive activities of Phyllanthus niruri spray-dried standardized extract}

\author{
Cínthia R. C. Porto, ${ }^{1}$ Luiz A. L. Soares, ${ }^{1,2}$ Tatiane P. Souza, ${ }^{3}$ \\ Pedro R. Petrovick, ${ }^{4}$ Ibson L. Lyra, ${ }^{5}$ Raimundo F. Araújo Júnior, ${ }^{6}$ \\ Silvana Maria Zucolotto Langassner, ${ }^{7}$ Aurigena A. A. Ferreira, ${ }^{8}$ \\ Gerlane C. B. Guerra ${ }^{*, 8}$
}

\begin{abstract}
${ }^{1}$ Programa de Pós-graduação em Ciências Farmacêuticas, Universidade Federal do Rio Grande do Norte, Brazil,

${ }^{2}$ Departamento de Ciências Farmacêuticas, Universidade Federal de Pernambuco, Brazil,

${ }^{3}$ Faculdade de Ciências Farmacêuticas, Universidade Federal do Amazonas, Brazil, ${ }^{4}$ Programa de Pós-graduação em Ciências Farmacêuticas, Faculdade de Farmácia, Universidade Federal do Rio Grande do Sul, Brazil,

${ }^{5}$ Departamento de Biofísica e Farmacologia, Universidade Federal do Rio Grande do Norte, Brazil,

${ }^{6}$ Departamento de Morfologia, Universidade Federal do Rio Grande do Norte, Brazil,

${ }^{7}$ Departamento de Ciências Farmacêuticas, Universidade Federal de Pernambuco, Brazil,

${ }^{8}$ Departamento de Biofísica e Farmacologia, Universidade Federal do Rio Grande do Norte, Brazil.
\end{abstract}

\begin{abstract}
Phyllanthus niruri L., Euphorbiaceae, spray-dried standardized extract was studied for its anti-inflammatory and antinociceptive activities in adult albino rats and mice. The anti-inflammatory effect of spray-dried standardized extract was observed in carrageenan-induced paw edema and thioglycolate-induced leukocyte migration, while antinociceptive effects were observed using Randall \& Selitto, tail flick, and hot plate tests. This study showed that intraperitoneal spray-dried standardized extract at 100 , 200,800 , or $1600 \mathrm{mg} / \mathrm{kg}$ reduced the vascular response in the inflammatory process of paw edema induced by $1 \%$ carrageenan. Oral spray-dried standardized extract at 100 or $200 \mathrm{mg} / \mathrm{kg}$ inhibited leukocyte migration to the site of inflammation induced by $3 \%$ thioglycolate. In rats, at 100 and $200 \mathrm{mg} / \mathrm{kg}$ intraperitoneally, the extract exhibited a marked peripheral analgesic effect in a Randall \& Selitto assay and showed significant central analgesic activity in a hot plate and tail flick assay. In conclusion, this study suggested that Phyllanthus niruri spray-dried standardized extract has potent inflammatory and antinociceptive activities and that these activities are not modified by standard drying process, making it feasible to use the dry extract standardized to obtain a phytotherapic preparation and thus validating its use for the treatment of pain and inflammation disorders.
\end{abstract}

\section{Introduction}

Phyllanthusniruri L., Euphorbiaceae, popularly known as "stonebreaker," is a small plant widely distributed throughout the tropical and subtropical regions of various countries, including Brazil. Due to its impressive preclinical therapeutic potential, extracts of species of the genus Phyllanthus have been evaluated to treat hypertension, jaundice, diabetes, hypercalciuria, urolithiasis, intestinal infections, diabetes, and hepatitis
B (Calixto et al., 1995). Phytochemicals isolates of $P$. niruri exhibit different structural characteristics with various pharmacological actions. For example, lignans have excellent hepatoprotective (Chang et al., 2003; Yan et al., 2009) and anti-viral properties (Gnabre et al., 1996), whereas terpenes exhibit anti-microbial activities (Popova et al., 2009). Flavonoids from Phyllanthus niruri have been shown to have anti-oxidant (Hayashi et al., 2012), antileishmanial (Muzitano et al., 2006), and anti-inflammatory properties (Guardia et al., 2001). 
$P$. amarus, $P$. orbiculatus, $P$. fraternus, $P$. stipulates and $P$. niruri have long-lasting antinociceptive properties when tested in nociceptive models such as acetic acid-induced abdominal contortions, and formalin and capsaicin-induced paw-licking; however, the underlying mechanisms of their analgesic effects remain unknown (Santos et al., 1995, Santos et al., 2000). Several bioactive molecules such as lignans, phyllanthin, hypophyllanthin, flavonoids and tannins have been found in P. niruri (Rajeshkumar et al., 2002).

Acute toxicity studies of aqueous leaf extracts of P. niruri found an LD50 greater than $5000 \mathrm{mg} / \mathrm{kg}$ b.w. with no adverse effect of this dose after a single administration (Asare et al., 2011). Cytotoxicity and genotoxicity studies confirmed that $P$. niruiri extract is generally nontoxic for acute oral administration of $P$. niruri whole plant extract in mice, at $300 \mathrm{mg} / \mathrm{kg}$ body weight (Asare et al., 2012).

Regarding the advantages of solid dosage forms such as content uniformity, stability and the production possibilities; several authors has studied the development of herbal dried products. However, the drier process can provide chemical instabilities and/or pharmacological inactivation (De Souza et al., 2006; Soares et al., 2003). Therefore, in view of the standardization process for obtaining of Phyllanthus niruri spray-dried extract, the aim of this study was to evaluate, using animal models of inflammation and pain, if the activities anti-inflammatory and antinociceptive this plant, are not inactivated by standard drying process.

\section{Materials and Methods}

\section{Plant material}

The aerial parts of Phyllanthus niruri L., Euphorbiaceae, were supplied by the 'Centro Pluridisciplinar de Pesquisas Químicas e Biológicas from the Campinas State University, Brazil. The plant was dried at $40{ }^{\circ} \mathrm{C}$ for a week in an air oven. Separated leaves and branches were reduced in a knife mill (Retsch SK1). A voucher specimen is deposited at the Herbarium of the Federal University of Rio Grande do Sul under number ICN 111765.

\section{Dry product preparation}

The dried and ground aerial parts from $P$. niruri were used to prepare aqueous extracts by decoction, using raw material in distilled water $(7.5 \%$; w $/ v)$. The aqueous extract was dried using a Niro Atomizer Production Minor spray drier to obtain the dried product (SDEPN). Colloidal silicon dioxide (Aerosil ${ }^{\circledR} 200$ ) was used as a drying agent at $30 \%(\mathrm{w} / \mathrm{w})$ based on the dry residue of the extracted solution. The SDEPN was standardized as $12.33 \mathrm{mg} / \mathrm{g}$ of gallic acid by HPLC, for De Souza et al., 2006 and as $99.4 \mathrm{mg} / \mathrm{g}$ total flavonoids by UV/VIS for Soares et al. (2003).

\section{Animals}

Mus musculus Swiss male mice (18-30 g), and Rattus norvegicus albinus Wistar rats (150-350 g) were obtained from the breeding colony of the Federal University of Rio Grande do Norte. Animals were held in a temperature-controlled room at $25 \pm 2{ }^{\circ} \mathrm{C}$ in $12 \mathrm{~h}$ light-12 h dark cycles, with ad libitum access to food and water. They received only water for $12 \mathrm{~h}$ before each experiment. All efforts were made to minimize discomfort and the number of animals used. Animal care and research protocols were based on principles and guidelines approved by the Guide for the Care and Use of Laboratory Animals (NIH publication No: 85-23, revised in 1985) and the protocols used were previously approved by the local Animal Ethics Committee.

\section{Carrageenan-induced paw edema}

Male mice $(\mathrm{n}=6)$ were treated with PnSDE $(100,200,800,1600 \mathrm{mg} / \mathrm{kg}$, i.p.). After $60 \mathrm{~min}$ an acute inflammatory process was induced in the subplantar region of the right paw with carrageenan $(1 \% \mathrm{w} / \mathrm{v}, 50$ $\mu \mathrm{L})$. The positive control group $(\mathrm{n}=6)$ received a sterile saline solution $(5 \mathrm{~mL} / \mathrm{kg}$, i.p. $)$ before induction of the inflammatory process, while the negative control group $(n=6)$ received only intraperitoneal saline solution injection without inflammatory induction. The standard group $(\mathrm{n}=6)$ was treated with diclofenac sodium $(100$ $\mathrm{mg} / \mathrm{kg}$, i.p.) before inflammation induction. After $4 \mathrm{~h}$, paw volume was measured with an analytical balance (as described by Freire et al., 2003) and the weight difference between right and left paws indicated the degree of inflammation.

\section{Leukocyte migration}

The leukocyte migration test was conducted in mice as previously described (Ribeiro et al., 1991). Test group animals $(n=6)$ received the PnSDE $(100$ or $200 \mathrm{mg} / \mathrm{kg}$ ) orally, $60 \mathrm{~min}$ before induction of inflammation by thioglycolate $(3 \% \mathrm{w} / \mathrm{v}, 100 \mu \mathrm{L})$ into the peritoneal cavity. The standard group was treated with dexamethasone $(0.7 \mathrm{mg} / \mathrm{kg})$ subcutaneous, $60 \mathrm{~min}$ before induction of inflammation. The positive control group received sterile saline solution $(5 \mathrm{~mL} / \mathrm{kg}, i . p),$. min before induction of inflammation by thioglycolate. The negative control group received only saline $(5 \mathrm{~mL} /$ $\mathrm{kg}$, i.p.). Thioglycolate was injected into the peritoneal cavities, 60 min after administration of the substances, 
and leukocyte migration was evaluated $4 \mathrm{~h}$ after the stimulus. Animals were sacrificed and peritoneal cavity cells were harvested with $3 \mathrm{~mL}$ of PBS. The number of total cells was counted in a Neubauer chamber. Results were expressed as number of neutrophils/cavity.

\section{Randall Selitto assay}

The pain threshold of the inflamed, edematous right hind paw of the rats subjected to constant force was examined by the Randall Selitto assay (1957). Initially, animals (male Wistar rats, $\mathrm{n}=6$ ) received an intraplantar injection of carrageenan $(1 \% \mathrm{w} / \mathrm{v}, 0.1 \mathrm{~mL})$ in sterile saline solution. After $60 \mathrm{~min}$ of inflammation induction, 100 or $200 \mathrm{mg} / \mathrm{kg}$ of PnSDE was administered in the test groups while the saline solution $(5 \mathrm{~mL} / \mathrm{kg}$, p.o. $)$ was given to the control group and diclofenac sodium (100 $\mathrm{mg} / \mathrm{kg}$, i.p.) was administered to the standard group. At 1,3 , and $4 \mathrm{~h}$, pressure was applied to the inflamed paw using an analgesiometer (model EFF 440, Insight Brazil), generating linearly increasing force, until the animal produced a response characterized by removal of the paw, interpreted as mechanical hypernociception.

\section{Tail flick test}

The tail flick test (Analgesiometer model EFF 300 , Insight Brazil) was performed as described by Kuraishi et al. (1983), with slight modifications. Room temperature was maintained at $23 \pm 2{ }^{\circ} \mathrm{C}$. Animals (male Wistar rats, $n=6$ ) were placed with the tail over a metal filament where radiant heat was applied using a flick unit. The time before the tail was removed from the metal filament was recorded. Two readings were taken every $30 \mathrm{~min}$. The first determine the animal's adaptation to the apparatus; the second was used to rule out animals with a baseline latency of over $15 \mathrm{~s}$. The test group received PnSDE (100 or $200 \mathrm{mg} / \mathrm{kg}$, i.p.), the standard group received morphine $(5 \mathrm{mg} / \mathrm{kg}$, i.p. $)$, and the control group received saline solution $(5 \mathrm{~mL} /$ $\mathrm{kg}$, i.p.) after the second reading, and latency time to withdraw the tail from the metal filament was recorded at $0.5,3,4$, and $5 \mathrm{~h}$ after substance administration.

\section{Hot plate test}

The hot plate test used in this study was as described by Kuraishi et al. (1983), with slight modifications. A hot plate (model EFF 361, Insight Brazil) was used to determine the analgesic effect of morphine $(5 \mathrm{mg} / \mathrm{kg}$, i.p.) or PnSDE (100 and $200 \mathrm{mg} /$ $\mathrm{kg}$, i.p.). Plate temperature was maintained at $5 \pm 1$ ${ }^{\circ} \mathrm{C}$. Male mice $(\mathrm{n}=6)$ were placed individually onto the hot plate to obtain a nociceptive response to the radiant heat. Paw licking or jumping was interpreted as a nociceptive response to thermal stimulation. The time before the animal licked its paws or jumped was recorded (response time). Two readings were taken every $30 \mathrm{~min}$. The first reading was determined the animal's adaptation to the apparatus and the second was used to exclude animals with a baseline latency of over 15 s. The test group received PnSDE (100 or $200 \mathrm{mg} /$ $\mathrm{kg}$, i.p.), the standard group received morphine $(5 \mathrm{mg} /$ $\mathrm{kg}, i . p$.), and the control group received saline solution $(5 \mathrm{~mL} / \mathrm{kg}$, i.p.) after the second reading. Response time was recorded at $0.5,2$, and $3 \mathrm{~h}$.

\section{Statistical analysis}

Control group data were treated as basal values. All experimental data were recorded as mean \pm SEM. Results were statistically evaluated by one-way analysis of variance (ANOVA) and using Student's $t$-test. The level of statistical significance was $p<0.05$. The analysis of results and construction of graphs were performed using GraphPad Prism version 5.04.

\section{Results}

Carrageenan-induced paw edema and leukocyte migration inhibition

As shown in Figure 1, PnSDE at doses of $100,200,800$, or $1600 \mathrm{mg} / \mathrm{kg}$ significantly inhibited carrageena-induced edema $(p<0.001, p<0.001, p<0.01$ and $p<0.001$, respectively), compared to the positive control group (carrageena-1\% w/v, $50 \mu \mathrm{L}$ ). The animals that received diclofenac $(100 \mathrm{mg} / \mathrm{kg})$ showed a significant reduction in edema production compared to the positive control group $(p<0.001)$. As shown in Figure 2, pretreatment with PnSDE at doses of 100 or $200 \mathrm{mg} / \mathrm{kg}$ inhibited leukocyte migration compared to the positive control group $(p<0.001)$.

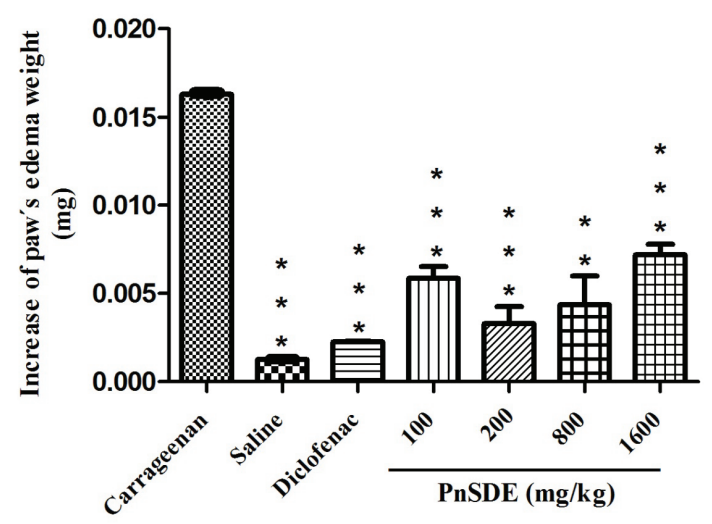

Figure 1. Effects of Phyllanthus niruri spray-dried standardized extract (PnSDE) on the carrageenan-induced paw edema. ANOVA and Student's t-test were used. ${ }^{*} p<0.05$, $* * p<0.01, * * * p<0.001$. 


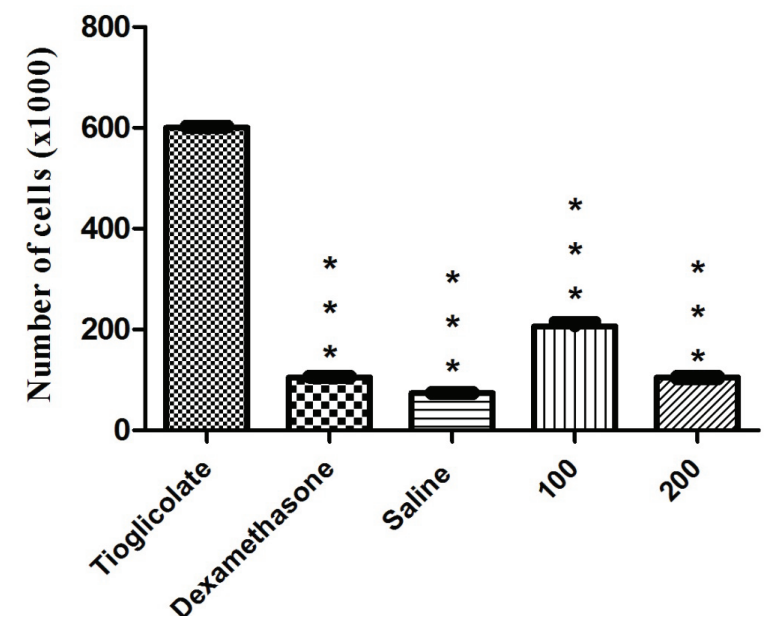

Figure 2. Effects of Phyllanthus niruri spray-dried standardized extract (PnSDE) on the treatment of thioglycolate-induced neutrophil migration to peritoneal cavity. ANOVA and Student's t-test were used. $* p<0.05, * * p<0.01, * * * p<0.001$.

\section{Randall and Selitto test}

As shown in Figure 3, PnSDE induced a strong peripheral analgesic effect compared to the positive control group at administered doses or 100 or $200 \mathrm{mg} /$ $\mathrm{kg}$ after $1(p<0.001$ and $p<0.05$, respectively) 3 , and $4 \mathrm{~h}$ $(p<0.001)$. The standard group, which received diclofenac $(100 \mathrm{mg} / \mathrm{kg})$, provoked an analgesic activity compared to the control group, at $1(p<0.01), 3$, and $4 \mathrm{~h}(p<0.001)$ after drug administration.

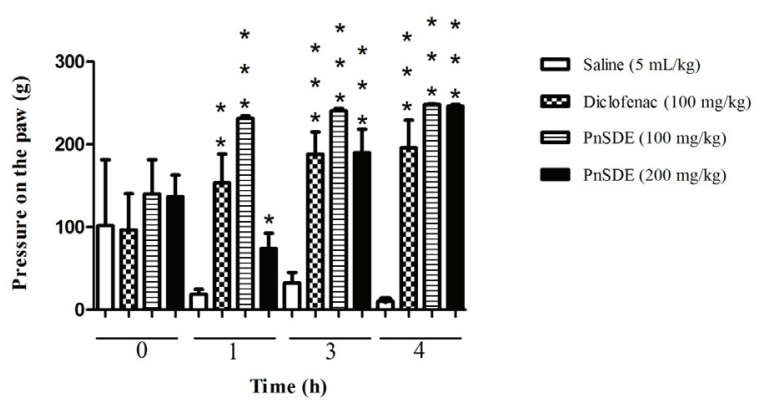

Figure 3. Effects of Phyllanthus niruri spray-dried standardized extract (PnSDE) on the Randall \& Selitto test. ANOVA and Student's t-test were used. ${ }^{*} \mathrm{p}<0.05, * * p<0.01$, $* * * p<0.001$.

\section{Tail flick test}

Compared to the control group, $100 \mathrm{mg} / \mathrm{kg}$ of PnSDE exhibited significant central analgesic activity after 0.5 and $5 \mathrm{~h}(p<0.001)$, and 3 and $4 \mathrm{~h}(p<0.01)$. Administration of $200 \mathrm{mg} / \mathrm{kg}$ of PnSDE provoked analgesic activity after $0.5,3,4$, and $5 \mathrm{~h}(p<0.05)$ compared to the control group. The standard group, which received $5 \mathrm{mg} / \mathrm{kg}$ of morphine, showed strong analgesic activity compared to the control group, 0.5 $(p<0.001)$ at 3,4 , and $5 \mathrm{~h}(p<0.05)$ after administration (Figure 4).

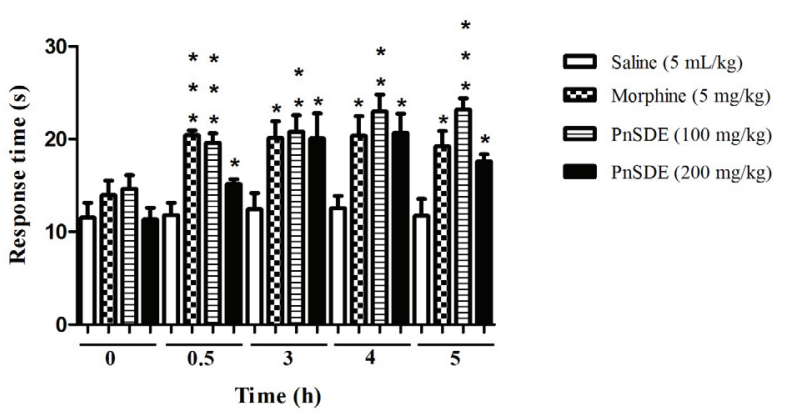

Figure 4. Effects of Phyllanthus niruri spray-dried standardized extract (PnSDE) on the tail flick test. ANOVA and Student's t-test were used. ${ }^{*} p<0.05, * * p<0.01$, $* * * p<0.001$.

\section{Hot plate test}

Administration of $100 \mathrm{mg} / \mathrm{kg}$ PnSDE induced central analgesic activity at $0.5(p<0.05), 2(p<0.05)$, and $3 \mathrm{~h}(p<0.05)$ compared to the control group. Administration of $200 \mathrm{mg} / \mathrm{kg}$ of PnSDE provoked a strong analgesic activity after $0.5 \mathrm{~h}(p<0.05), 2 \mathrm{~h}$ $(p<0.01)$ and $3 \mathrm{~h}(p<0.05)$ compared to the control group. The standard group, which received $5 \mathrm{mg} / \mathrm{kg}$ of morphine, exhibited analgesic activity compared to the control groupat $0.5 \mathrm{~h}(p<0.01), 2 \mathrm{~h}(p<0.05)$, and $3 \mathrm{~h}$ $(p<0.01)$ after administration (Figure 5).

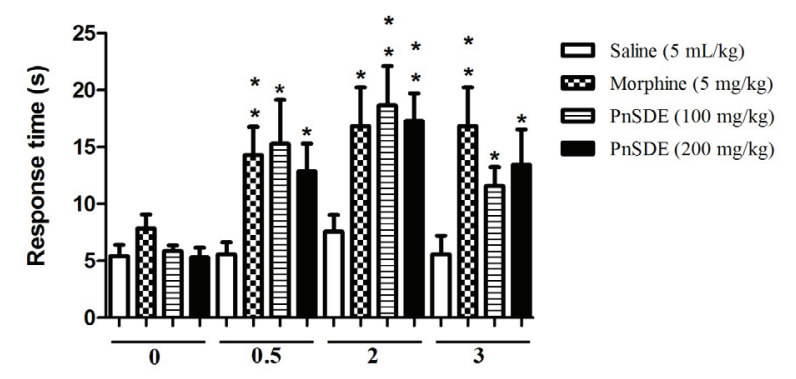

Figure 5. Effects of Phyllanthus niruri spray-dried standardized extract (PnSDE) on a hot plate test. ANOVA and Student's t-test were used. ${ }^{*} p<0.05, * * p<0.01, * * * p<0.001$.

\section{Discussion}

This study try established a scientific basis for the use of the Phyllanthus niruri L., Euphorbiaceae, spraydried standardized extract, with the aim of evaluate, using animal models of inflammation and pain, if the activities anti-inflammatory and antinociceptive are not inactivated by standard drying process.

Actually, dried extract are often used as therapeutically active material in the manufacture of phytopharmaceuticals. Several advantages are 
attributed to this procedure of extract manufacture such as, chemical and physical stabilities; ease to handle, and use as intermediary to produce solid dosage forms such as capsules and tablets (De Souza et al., 2006; Soares et al., 2003). The assessment of stability of such extracts plays an important role on the product effectiveness. The chemical analysis is the procedure of choice to evaluate the stability of pharmaceutical products. However, unlike synthetic drugs, the pharmacological activity from herbal drugs or Phytopharmaceuticals is a result of joint action of a group of substances, and can be affected by transformations procedures of the raw material (Weerakkody et al., 2011; Wagner, 2011).

This study showed that administration of PnSDE produced consistent anti-inflammatory and antinociceptive effects in different models of inflammation and pain. The anti-inflammatory effect of PnSDE was observed in carrageenan-induced paw edema and thioglycolate-induced leukocyte migration, while antinociceptive effects were observed using (Randall \& Selitto), tail flick, and hot plate tests.

The subcutaneous administration of carrageenan provokes an acute and progressive increase in the mouse paw volume in response to the production of diverse inflammatory mediators. This edema, which is proportional to the intensity of the response to inflammation, is a useful parameter for evaluating anti-inflammatory activity in new compounds. Experimental data obtained in the paw edema test must be compared with data from another anti-inflammatory activity assessment model, considering that vasoactive substances devoid of anti-inflammatory effects may interfere with this process (Di Rosa et al., 1971).

The method of leukocyte migration is an acute inflammation model frequently used in studies of new anti-inflammatory drugs, in which leukocyte migration to the inflammation site occurs. Quantifying this migration enables the evaluation of new drugs that could interfere with the inflammatory process (Ribeiro et al., 1991). This method was chosen for this study since it is the most prominent experimental model used to evaluate anti-inflammatory effects of natural products in the search for new drugs (Sugishita et al., 1981; Posadas et al., 2003).

In carrageenan-induced paw edema, PnSDE at doses of $100,200,800$, or $1600 \mathrm{mg} / \mathrm{kg}$ injected intraperitoneally, evoked considerable edema reduction, suggesting that PnSDE inhibited different chemical inflammation mediators. This finding was comparable to that obtained for drugs such as dexamethasone and diclofenac, which are widely used for anti-inflammatory purposes. Confirming the antiinflammatory action of PnSDE, leukocyte migration to the peritoneal cavity was greatly reduced with 100 and $200 \mathrm{mg} / \mathrm{kg}$ of extract. Inhibition of leukocyte migration in inflammation models is considered a strong indicator of anti-inflammatory activity (Faurschou \& Borregaard, 2003).

Many methods for assessing central antinociceptive and peripheral activity in animals have been used. These involve the application of painful stimuli to observe animal response time. Thus, we observed the ability of PnSDE to eliminate or reduce pain intensity or delay the stimulus response. Randall \& Selitto (1957), tail flick and hot plate tests are used to evaluate the level of peripheral and central action of analgesic drugs.

In the Randall \& Selitto (1957) method, pain is caused by the production of inflammatory mediators induced by intraplantar carrageenan injections and intensified by mechanic pressure exerted by an analgesiometer. In the tail flick and hot plate methods, pain is mediated by central mechanisms, where nociceptive stimuli trigger spinal reflexes (Archana et al., 2005). The tail flick method allows collection of information on the mechanism and location of the antinociceptive activity detected, since the tail flick reflex is spinally integrated (Gianni et al., 2007).

In the Randall \& Selitto (1957) test, after administration of PnSDE at doses of $100 \mathrm{mg} / \mathrm{kg}$ and 200 $\mathrm{mg} / \mathrm{kg}$, peripheral analgesic activity with an increased nociceptor threshold to painful stimuli compared to the control group was observed. These results were similar to those obtained with the diclofenac, a widely used analgesic. In the tail flick and hot plate methods, PnSDE at doses of 100 and $200 \mathrm{mg} / \mathrm{kg}$ showed significant central analgesic activity compared to the control group, as evidenced by an increase in response time to thermal stimulus. These results were comparable and even higher than those obtained with morphine, a standard, widely used drug.

Studies performed by members of our group found that PnSDE is rich in phenolic compounds, especially flavonoids (Soares et al., 2003; De Souza et al., 2002). These compounds exhibit known pharmacological activities, such as anti-inflammatory and antinociceptive (Ramesh et al., 1998; Toker et al., 2004; Kupeli \& Yesilada, 2007; Aquila et al., 2009; Dong et al., 2010); antioxidant and cytotoxic effects (Heim et al., 2002; Susant et al., 2007; Dong et al., 2010). Thus, pharmacological activities displayed by PnSDE seem to be related to the presence of flavonoids, especially quercetin (Soares et al., 2003). Many flavonoids have been studied for their anti-inflammatory activities in various experimental models, both in vitro and in vivo.

In conclusion, this study suggested that Phyllanthus niruri spray-dried standardized extract (PnSDE), has potent inflammatory and antinociceptive activities and that these activities are not modified by standard drying process, making it feasible to use 
the dry extract standardized to obtain a phytotherapic preparation and thus validating its use for the treatment of pain and inflammation disorders.

\section{Acknowledgments}

The authors are grateful to $\mathrm{CNPq}$ (470179/2009-0) for financial support.

\section{References}

Aquila S, Giner RM, Recio MC, Spegazzini ED, Ríos JL 2009. Anti-inflammatory activity of flavonoids from Cayaponia tayuya roots. J Ethnopharmacol 121: 333337.

Archana P, Tandan SK, Chandra S, Lal J 2005. Antipyretic and analgesic activities of Caesalpinia bonducella seed kernel extract. Phytother Res 19: 376-381.

Asare GA, Addo P, Bugyei K, Gyan B, Adjei S, Otu-Nyarko LS, Wiredu EK, Nyarko A 2011. Acute toxicity studies of aqueous leaf extract of Phyllanthus niruri. Interdiscip Toxicol 4: 206-210.

Asare GA, Bugyei K, Sittie A, Yahaya ES, Gyan B, Adjei S, Addo P, Wiredu EK, Adjei DN, Nyarko AK 2012. Genotoxicity, cytotoxicity and toxicological evaluation of whole plant extracts of the medicinal plant Phyllanthus niruri (Phyllanthaceae). Genet Mol Res 11: 100-111.

Calixto JB, Santos RSA, Filho CV, Yune SRA 1995. Analysis of the mechanisms underlying the antinociceptive effect of the extracts of plants from the genus Phyllanthus. Gen Pharmacol 26: 1499-1506.

Chang CC, Lien Y, Karin CS, Liu C, Lee S 2003. Lignans from Phyllanthus urinaria. Phytochemistry 63: 825833.

De Souza TP, Holzschuh MH, Lionc MI, González OG, Petrovick PR 2002. Validation of a LC method for the analysis of phenolic compounds from aqueous extract of Phyllanthus niruri aerial parts. J Pharmaceut Biomed 30: 351-356.

De Souza TP, Gómez-Amoza JL, Matínez-Pacheco R, Petrovick PR 2006. Compression behavior of formulations from Phyllantus niruri spray dried extract. Pharmazie 61: 213-217.

Di Rosa M, Giroud JP, Willoughby DA 1971. Studies on the mediators of the acute inflammatory response induced in rats in different sites by carrageenin and turpentine. J Pathol 104: 15-29.

Dong W, Wei T, Guang-Ming Y, Bao-Chang C 2010. Antiinflammatory, antioxidant and cytotoxic activities of flavonoids from Oxytropis falcata Bunge. Chinese $J$ Nat Med 8: 461-465.

Freire MGM, De Souza IA, Silva ACM, Macedo MLR, Lima MS, Tamashiro WMSC, Antunes E, Marangoni S 2003. Inflammatory responses induced in mice by lectin from Talisia esculenta seeds. Toxicon 42: 275280.

Faurschou M, Borregaard N 2003. Neutrophil granules and secretory vesicles in inflammation. Microbes Infect 5: 1317-1327.

Gianni GP, Rodrigues ST, Medeiros SH, Muccillo-Baish AL 2007. Uso de modelos animais para avaliar o potencial antinociceptivo dos produtos de origem natural. Vittalle 19: 35-44.

Gnabre JN, Itob Y, Mab Y, Huanga RC 1996. Isolation of anti-HIV-1 lignans from Larrea tridentata by countercurrent chromatography. J Chromatogr 719: 353364.

Guardia T, Rotelli AE, Juarez AO, Pelzer LE 2001. Antiinflammatory properties of plant flavonoids. Effects of rutin, quercetin and hesperidin on adjuvant arthritis in rat. Farmaco 56: 683-687.

Hayashi Y, Matsushima M, Nakamura T, Shibasaki M, Hashimoto N, Imaizumi K, Shimokata K, Hasegawa Y, Kawabe T 2012. Quercetin protects against pulmonary oxidant stress via heme oxygenase-1induction in lung epithelial cells. Biochem Biophl Res Co 417: 169174.

Heim KE, Tagliaferro AR, Bobilya DJ 2002. Flavonoid antioxidants: chemistry, metabolism and structureactivity relationships. $J$ Nutr Biochem 13: 572-584.

Kupeli E, Yesilada E 2007. Flavonoids with anti-inflammatory and antinociceptive activity from Cistus laurifolius L. leaves through bioassay-guided procedures. $J$ Ethnopharmacol 112: 524-530.

Kuraishi Y, Harada Y, Aratani S, Satoh M, Takagi H 1983. Separate involvement of the spinal noradrenergic and serotonergic systems in morphine analgesia: the differences in mechanical and thermal algesic tests. Brain Res 273: 245-252.

Muzitano MF, Cruz EA, De Almeida AP, Da Silva SA, Kaiser CR, Guette C, Rossi-Bergmann B, Costa SS 2006. Quercitrin: an antileishmanial flavonoid glycoside from Kalanchoe pinnata. Planta Med 72: 81-83.

Popova MP, Chinou IB, Marekov IN, Bankova VS 2009. Terpenes with antimicrobial activity from Cretan própolis. Phytochemistry 70: 1262-1271.

Posadas IMC, Terencio MR, Randazzo A, Paloma RG, Payá M, Alcaraz MJ 2003. Inhibition of the NF- $\square$ B signaling pathway mediates the anti-inflammatory effects of petrosaspongiolide M. Biochem Pharmacol 65: 887-895.

Rajeshkumar NV, Joy KL, Kuttan G, Ramsewak RS, Muraleedharan GN, Kuttan R 2002. Antitumour and anticarcinogenic activity of Phyllanthus amarus extract. J Ethnopharmacol 81: 17-22.

Ramesh M, Rao YN, Rao AVNA, Prabhakar MC, Rao CS, Muralidhar N, Reddy BM 1998. Antinociceptive and anti-inflammatory activity of a flavonoid isolated from Caralluma attenuate. J Ethnopharmacol 62: 63- 
66.

Randall LO, Selitto JJ 1957. A method for measurement of analgesic activity of inflamed tissue. Arch Int Pharmacod T 111: 409-419.

Ribeiro RA, Flores CA, Cunha FQ, Ferreira SH 1991. Il-8 causes in vivo neutrophil migration by a cell-dependent mechanism. Immunology 73: 472-477.

Santos ARS, Filho VC, Yunes RA, Calixto JB 1995. Further studies on the antinociceptive action of the hydroalcoholic extracts from plants of the genus Phyllanthus. J Pharm Pharm Sci 47: 66-71.

Santos ARS, De Campos ROP, Miguel OG, Filho VC, Siani AC, Yunes RA, Calixto JB 2000. Antinociceptive properties of extracts of new species of plants of the genus Phyllanthus (Euphorbiaceae).

Ethnopharmacol 72: 229-238.

Soares LAL, Bassani VL, González OG, Petrovick PR 2003. Total flavonoid determination for the quality control of aqueous extractives from Phyllanthus niruri L. Acta Farm Bonaer 22: 203-207.

Sugishita E, Amagaya S, Ogihara Y 1981. Anti-inflammatory testing methods: comparative evaluation of mice and rats. J Pharmacobio-Dynam 4: 565-575.

Susanti D, Sirat HM, Ahmad F, Ali RM, Aimi N, Kitajima M 2007. Antioxidant and cytotoxic flavonoids from the flowers of Melastoma malabathricum L. Food Chem
103: 710-716

Toker G, Kupeli E, Memisoglu M, Yesilada E 2004. Flavonoids with antinociceptive and anti-inflammatory activities from the leaves of Tilia argentea (silver linden). $J$ Ethnopharmacol 95: 393-397.

Wagner H 2011. Synergy research: Approaching a new generation of phytopharmaceuticals. Fitoterapia 82: 34-37.

Weerakkod NS, Caffin N, Lambert LK, Turner MS, Dykes GA 2011. Synergistic antimicrobial activity of galangal (Alpinia galanga), rosemary (Rosmarinus officinalis) and lemon iron bark (Eucalyptus staigerana) extracts J Sci Food Agr 91: 461-468.

Yan F, Zhang Q, Jiao L, Han T, Zhang H, Qin L, Khalid R 2009. Synergistic hepatoprotective effect of Schisandrae lignans with Astragalus polysaccharides on chronic liver in jury in rats. Phytomedicine 16: 805-813.

\section{*Correspondence}

Gerlane Coelho Bernardo Guerra

Universidade Federal do Rio Grande do Norte, Centro de Biociências, Departamento de Biofísica e Farmacologia

Campus Universitário, BR 101, Lagoa Nova, 59072-970

Natal-RN, Brazil

Tel.: +55843215341 